\title{
IDENTIFICATION OF MAIZE LODGING: A CASE STUDY USING A REMOTELY PILOTED AIRCRAFT SYSTEM
}

\author{
Matheus G. Acorsi ${ }^{*}$, Maurício Martello², Graciele Angnes² \\ ${ }^{1 *}$ Corresponding author. "Luiz de Queiroz" College of Agriculture, University of São Paulo/ Piracicaba - SP, Brazil. \\ Email: 1matheusacorsi@gmail.com | ORCID ID: https://orcid.org/0000-0002-3318-7882
}

\section{KEYWORDS}

Crop surface model, structure from motion, canopy height, RGB.

\begin{abstract}
A common agricultural problem in many regions of Brazil is maize lodging, as a consequence of strong winds and rain which impacts on crop growth and yield. However, collecting data using ground-based, manual field measurement methods is inefficient. An emerging tool is the Remotely Piloted Aircraft System (RPAS), capable of delivering spatial data with high resolution and flexible periodicity. In this study, the potential to detect the maize lodging using crop surface models derived from RPAS was assessed. Our RPA-based approach uses a quantitative threshold to determine lodging percentage. The threshold values of plant height, used to detect the occurrence of lodging, were based on fixed and variable values. The validation of percentage lodging was performed using the RGB orthomosaic. The derived lodging estimates showed a very high correlation to the reference data. High correlations were observed for the fixed threshold at $60 \%\left(\mathrm{R}^{2}=\right.$ 0.93 , RSME $=8.72 \%$ ) and the variable thresholds, Jenks natural breaks and iso-clusters $\left(\mathrm{R}^{2}=0.92\right.$, RSME $=8.89 \%$ and $\mathrm{R}^{2}=0.92$, RSME $=9 \%$, respectively $)$. This study demonstrated the potential of the use of this technique, reducing the subjectivity of ground-based evaluation and the laborious traditional technique of lodging inference.
\end{abstract}

\section{INTRODUCTION}

Brazil is the third largest producer of maize in the world, with an estimated production of 92 million tons for the 2018/2019 harvest (FIESP, 2018). Maize is grown all over the country, being used as animal feed (60\%) and even in high technology products and the human food industry, due to its characteristics of having a high potential yield, chemical and nutritional quality (Embrapa, 2010). In maize crops, yield losses due to tipping (lodging and breaking) can reach up to $31 \%$ according to a study carried by Elmore (2013) that induced maize artificial lodging in Iowa. These results were also observed in commercial trials in Texas, in which lodging was approximately 15 to $21 \%$ negatively correlated to yield (Farfan et al., 2013).

Lodging refers to the permanent displacement of aerial portions of the plantations from the vertical position due to stem buckling (stem tipping) or failure of the groundroot anchorage system (root housing) (Wu \& Ma, 2016). The causes of lodging are varied, ranging from an excess of nitrogen, storm damage, soil bulk density, crop disease and overpopulation (Chu et al., 2017). Maize is one of the main crops affected by plant lodging, mostly because it makes mechanical harvesting difficult, leading to grain quality reduction and yield reduction (Wu \& Ma, 2016; Chu et al., 2017). Lodging maps can be useful during yield variability analysis, since lodging is considered a source of error in yield maps and should be removed. In addition, these maps can be further used to carry out in situ investigations and help in understanding its relation with environmental factors and management practices (Li et al., 2014; Chu et al., 2017; Liu et al., 2018). The maps are a useful tool for precision farming and applications that rely on spatial information regarding lodging, such as damage assessments for insurance purposes (Wilke et al., 2019).

Considering the importance of lodging detection, recent studies have explored alternatives to traditional lodging detection, which is laborious and subjective, and depends on point-wise ground data collection (Chu et al., 2017). Most of these studies have focused on the use of remote sensing techniques for lodging assessment, usually

\footnotetext{
2 “Luiz de Queiroz" College of Agriculture, University of São Paulo, Piracicaba - SP, Brazil.
} 
using data acquired by aerial platforms. Alternative methods to assess lodging have been tested using the spectral response of the canopy through vegetation indices such as NDVI (Han et al., 2018), thermal infrared images (Liu et al., 2018), surface models derived from LiDAR (Tilly et al., 2015), or crop surface models (CSMs) derived from RGB aerial imaging (Chu et al., 2017). CSMs are obtained by RGB imaging processing, using structure from motion (SfM) algorithms that generate $3 \mathrm{D}$ point clouds representing the surface of the crop canopy, which is highly correlated with plant height (PH) (Bendig et al., 2013). Since plant height is directly affected by lodging, some studies have used this parameter for lodging detection, analyzing plant height derived from RGB images and processed by SfM softwares (Chu et al., 2017; Malambo et al., 2018). Even though this technique has shown great potential, lodging detection is still a challenge. The main problem regarding lodging detection with the SfM approach is defining a threshold, which is the minimum $\mathrm{PH}$ to classify plant lodging. Most of the studies have used a predefined threshold, based on subjective inspections rather than mathematical analysis, compromising the possibility of reproducing this method for different crops and situations.

The aim of this study, therefore, was to assess the feasibility of CSM-based plant height information obtained from RGB imaging for lodging detection in maize. In order to develop a method that can be further reproduced, we tested different ways of determining a threshold, comparing predefined thresholds that are commonly used and thresholds obtained from mathematical approaches.

\section{MATERIAL AND METHODS}

\section{Study Area}

The study was carried out at the experimental area of the Federal Technological University of Paraná (UTFPR), located in the city of Dois Vizinhos, in the state of Paraná. The geographical coordinates are $25^{\circ} 41^{\prime} 27^{\prime \prime S}$ latitude and $53^{\circ} 5^{\prime} 52^{\prime \prime} \mathrm{W}$ longitude, at approximately $510 \mathrm{~m}$ above sea level. The soil at the site is classified as Distroferric Red Nitossol (Bhering et al., 2008). The maize field had a total area of $3,830 \mathrm{~m}^{2}$ (commercial variety P3431VYH), and was being grown without experimental treatments for silage production.

\section{RPA Flight and Image Acquisition}

Images were taken at noon on 12 May 2017, after an extreme weather event, with strong winds causing severe lodging damage to the crop, which was at grain filling stage (R3). The platform used was a DJI Phantom 3 Advanced multirotor (DJI, Shenzhen, Guangdong, China) remotely piloted aircraft, equipped with several embedded sensors, including the CMOS RGB image sensor (12 megapixels), which enabled obtaining images with a ground sample distance (GSD) of $0.023 \mathrm{~m} \mathrm{pixel}^{-1}$ at a height of $60 \mathrm{~m}$. The aircraft features a global navigation satellite system (GNSS) allowing the execution of a previous flight plan. The flight plan was developed using Drone Deploy software (DroneDeploy Inc., San Francisco, CA, USA). In this study, a lateral and longitudinal overlap of $80 \%$ between the images was set, ensuring the total coverage of the study area and enabling the reconstruction of the digital surface model. At the moment of image acquisition, the climate conditions were ideal, without the presence of clouds and wind.

For further georeferencing procedures, four ground control points (GCPs) were previously distributed and located in the field. The coordinates of the GCPs were measured following a Post-Processing Kinematic (PPK) method, with a double frequency (L1/L2) receiver as the base station (GTR-G ${ }^{2}$ TechGeo, Brazil) and a single frequency (L1) receiver as rover (GTR-ABT TechGeo, Brazil). The expected accuracy of the PPK method for the mentioned receivers is $0.005 \mathrm{~m}$ for both horizontal and vertical positioning.

\section{Canopy Height Model Generation}

The Agisoft Photoscan Professional software (Agisoft LLC, Saint Petersburg, Russia) was used to generate a dense cloud through an SfM algorithm, which was later converted into digital terrain and surface models (DTM and DSM) (Figure 1). The digital models are derived from $3 \mathrm{D}$ point clouds generated from a set of overlapping images and processed through SfM algorithms, which explores the photogrammetrics in order to reconstruct the 3D view of the scene (Malambo et al., 2018).

For DTM generation, it was necessary to filter the dense cloud by selecting the points of the terrain without the influence of the crop, which represents the soil level (Bendig et al., 2013). The classification was determined empirically, by testing different values for the factors and observing the relationship of the results with the orthomosaic. Thus, the following parameters were used: maximum angle $0.5^{\circ}$, maximum distance $0.1 \mathrm{~m}$ and cell size $10 \mathrm{~m}$.

Subsequently, the SfM was used to build a georeferenced orthomosaic of the covered area. The CSM was calculated by digital models (DTM and DSM), as expressed as [eq. (1)] (Hoffmeister et al., 2010):

$$
C S M=D S M-D T M
$$

Where:

CSM is the Crop Surface Model (m);

DTM is the Digital Terrain Model (m), and

DSM is the Digital Surface Model (m).

Digital models were generated under a uniform resolution of $23 \mathrm{~mm} \mathrm{pixel}^{-1}$. Using map algebra between the DSM (which represents the vegetation canopy) and the DTM (which represents ground level), allows a third model to be generated (called CSM), which was equivalent to plant height (Bendig et al., 2013). 


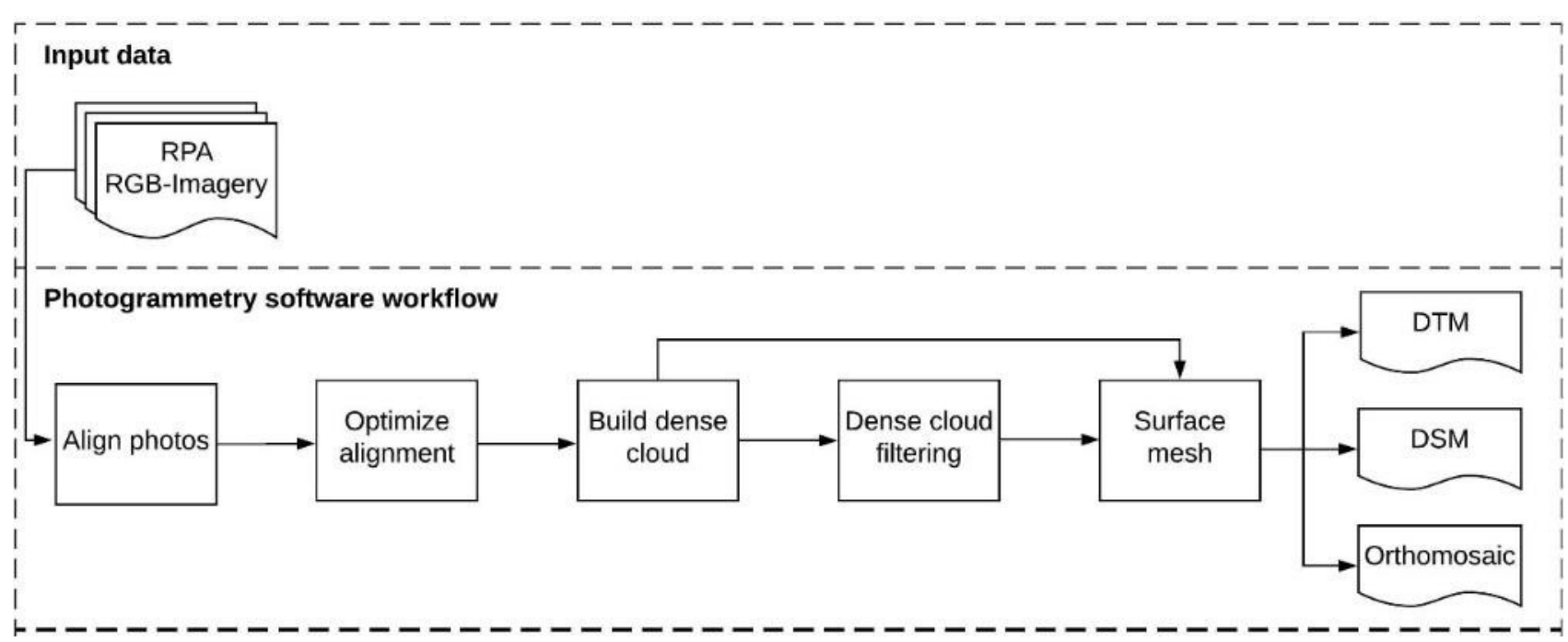

FIGURE 1. Workflow developed to generate DTM, DSM, and Orthomosaic using RPA-based imagery in Agisoft Photoscan Professional software.

\section{Identification of Maize Lodging}

Before identifying maize lodging, the height data was normalized (Equation 2) based on the maximum plant height. As recommended by Chu et al. (2017) and Malambo et al. (2018) we utilized the $99 \%$ percentile to represent the maximum plant height, avoiding the use of outliers to represent this value. The main advantage of the normalization process is that it can easily be replicated in other crops, allowing comparisons with other studies, because the normalized values are relative. The process was carried out using the raster calculator tool of ArcGIS.

$$
\text { Plant height normalized }(\%)=\frac{h * 100}{H}
$$

Where:

$$
\begin{aligned}
& h=\text { observed height }(\mathrm{m}) \text {, and } \\
& \mathrm{H}=\text { maximum height at percentile } 99 \%(\mathrm{~m}) .
\end{aligned}
$$

In order to identify the cut threshold between lodging and non-lodging plants, two methods were tested in this study, using both a fixed and variable parameter to establish the threshold. The fixed method followed the one proposed by Wilke et al. (2019) for lodging evaluation, in which four lodging percentage thresholds related to the max height $99 \%$ percentile were calculated: $80 \%, 70 \%, 60 \%$, and $50 \%$ of the plant height normalized reduction.

The variable methods were used to obtain thresholds automatically, using aspects of the distribution of sampled data throughout the whole area of study. Two unsupervised classification methods were used: Jenks Natural Breaks algorithm and iso-cluster, which are usually available in GIS softwares. Jenks Natural Breaks is a data clustering method designed to determine the best arrangement of values into different classes by minimizing the variance within classes and then maximizing the variance between classes (Jenks \& Caspall, 1971). On the other hand, the Iso Cluster is an algorithm that was specially developed to classify raster datasets automatically, applying the fuzzy ISODATA clustering to determine the characteristics of the natural groups of pixels ( $\mathrm{Li}$ et al., 2008).

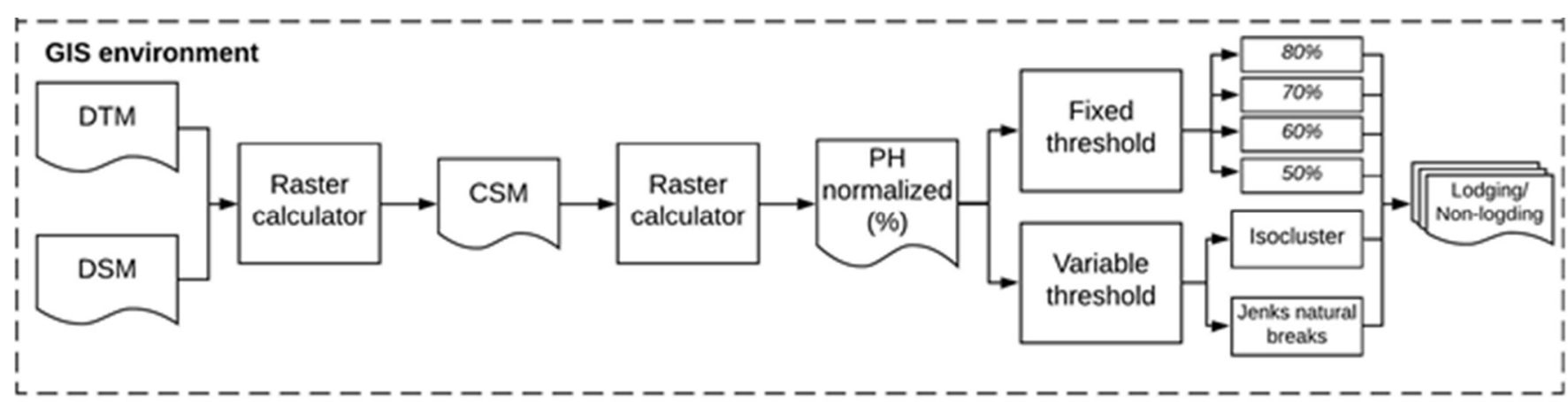

FIGURE 2. Workflow developed for lodging evaluation using DTM and DSM, developed in ArcGIS.

\section{Validating Lodging Percentage}

To analyze the proposed methods, 45 random validation polygons were distributed within the field (Figure 3a), each one with a sampling area of $12 \mathrm{~m}^{2}$. In each sample area, lodging was manually quantified using the RGB orthomosaic $(\mathrm{GSD}=0.023 \mathrm{~cm}$ ) (Figure 3a) and further compared with the lodging area determined by each method based on CSM (Figure 3a and 3b) using regression analysis, following the procedure proposed by Wilke et al. (2019). Since lodging areas could be easily identified due to the high spatial resolution orthomosaic, we could precisely quantify the lodging percentage area within each sampled area, which allowed the validation process of the methods tested in this study. 


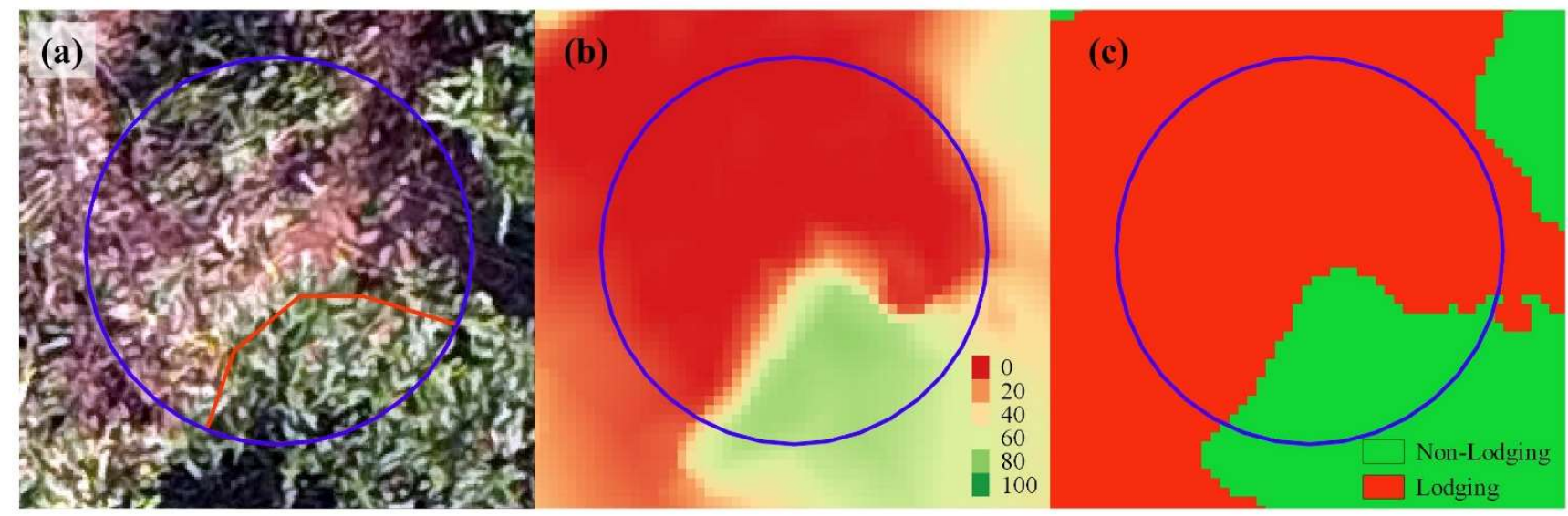

FIGURE 3. (a) High-resolution red/green/blue (RGB) orthomosaic used for manual validation of areas lodging, the circle in blue is the validation area and the red line is the limit of the area lodging and non-lodging. (b) Calculated plant height normalized (\%) in the region of interest. (c) Binary image calculated based on Jenks natural breaks lodging percentage threshold with areas lodging (red) and non-lodging (green).

\section{RESULTS AND DISCUSSION}

After image processing, the orthostatic image presented in Figure 4(a) was obtained. Figure 4 also contains the digital terrain (b) and surface models (c) generated. By overlaying the digital terrain and surface model, it was possible to extract PH as expressed by the CSM, which was further normalized (Figure 4d) by [eq. (2)]. By observing Figure 4d, it is possible to identify the areas that presented low values of plant height, indicating lodging plants.

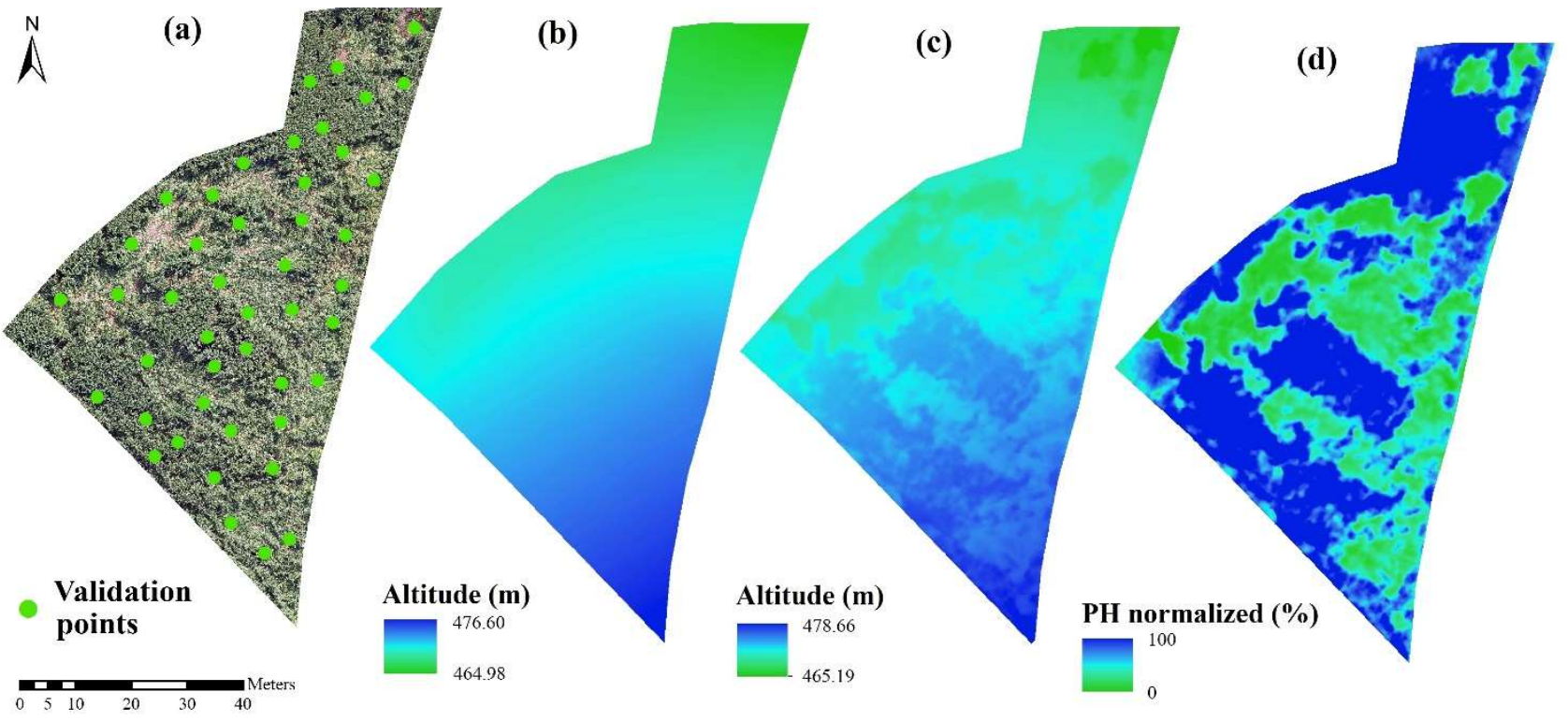

FIGURE 4. (a) Ortomosaic obtained through aerial images with 45 validation points. (b) Digital terrain model obtained through aerial images after filtration. (c) Digital surface model obtained through aerial images. (d) Plant height normalized obtained through subtraction between digital surface model and digital terrain model after normalized max height.

The canopy was the key factor in the classification of lodging. When anomalies were observed, the canopy structure was compromised. This factor was observed and suggested by other authors who evaluated lodging in maize and rice (Han et al., 2018; Chu et al., 2017; Yang et al., 2017). When the structure of the canopy presents anomalies, different angles of inclination occurs, reflecting the difference between plant height and soil level (Chu et al., 2017).

Figure 5 shows linear regression models obtained using the lodging area manually determined within the validation points using RGB orthomosaic versus and the lodging area automatically classified using thresholds fixed and variable. The methods used to determine a threshold value to classify areas presenting lodging was previously discussed by Wilke et al. (2019), comparing approaches where thresholds are usually chosen based on subjective decisions against mathematical approaches which use reference data for validation. The approach developed by Wilke et al. (2019) for the percentage evaluation of the performance provided less precision in the fixed values of cut $80 \%, 70 \%$ and $50 \%\left(\mathrm{R}^{2}=0.76,0.86\right.$, and 0.82 ; RMSE $=15.45 \%, 11.90 \%$, and $14.54 \%$, respectively), which lead to an underestimation of the $80 \%$ and $70 \%$ threshold cuts. 
This underestimation occurs because the method of cutting is more restrictive, only classifying areas that present severe lodging. On the other hand, the threshold of 50\% caused an overestimation, because classified border areas do not present lodging. This behavior was also observed by Wilke et al. (2019) when evaluating fixed values to determine lodging in the barley crop. However, the best threshold value observed in our study was found when using the $60 \%$ threshold $\left(\mathrm{R}^{2}=0.92, \mathrm{RMSE}=8.72 \%\right)$ which differed from the value found by Wilke et al. (2019), who found $\mathrm{R}^{2}=0.96$, and $\mathrm{RMSE}=7,66 \%$ for the $70 \%$ threshold, leading to an overestimation of $2 \%$.
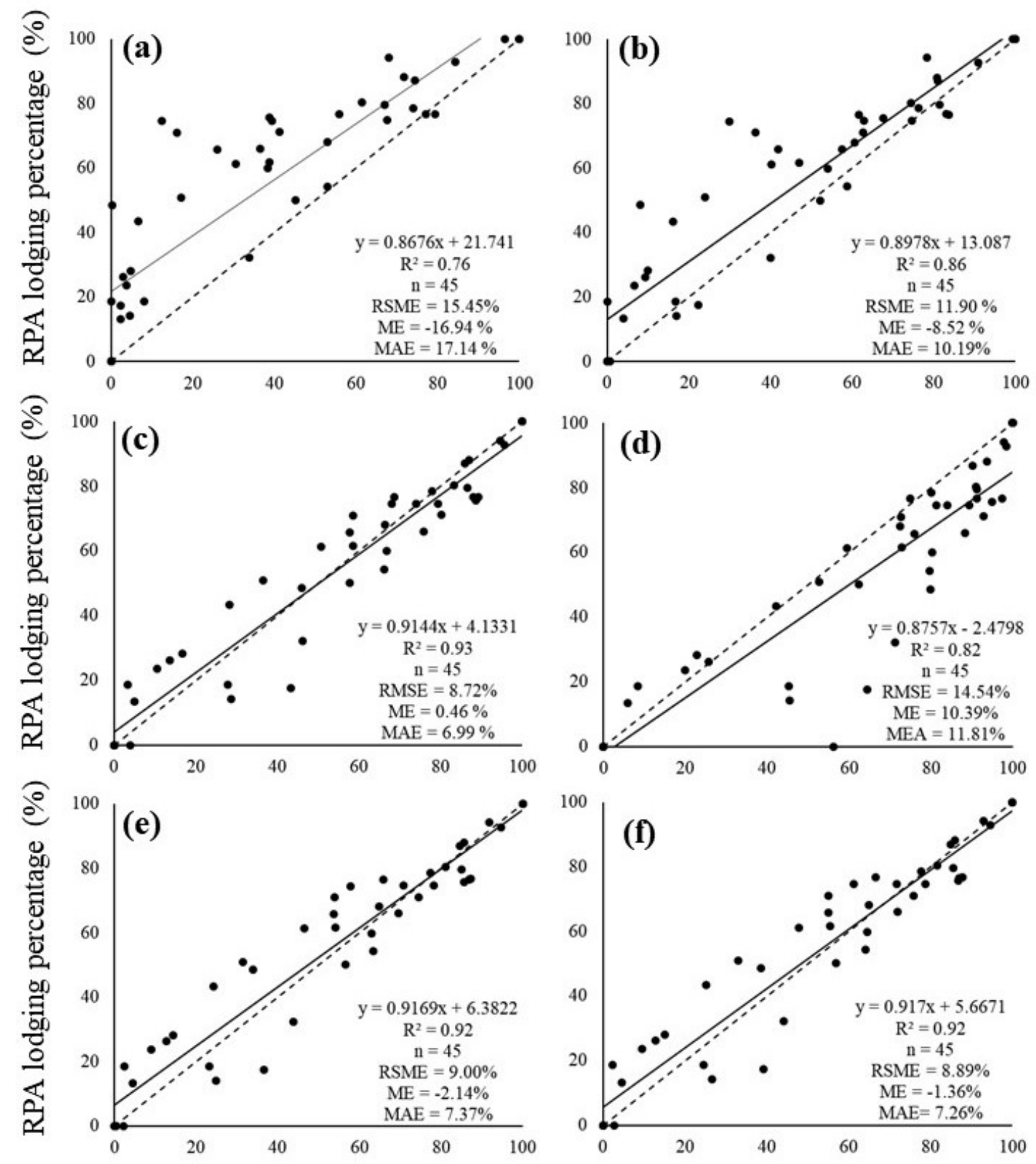

\section{Manually determined lodging percentage (\%)}

FIGURE 5. Scatter plots of manually determined lodging percentage and calculated RPA-based lodging percentage for (a) $80 \%$, (b) 70\%, (c) 60\%, (d) 50\%, (e) iso-cluster and (f) Jenks natural breaks. Black line represents regression line with $95 \%$ confidence interval; dotted line represents 1:1 line $(n=45)$. RMSE: root mean square error, ME: mean error, MAE: mean absolute error.

Figure 5 and Figure 6 present the spatial information of the lodging, where it is possible to observe that the fixed value of $70 \%$ and $80 \%$ underestimated the lodging areas, whereas the value of $50 \%$ presented an overestimation of the lodging. For the values of $60 \%$ and variable thresholds (Iso-cluster and Jenks), the data dispersion showed that the method did not present high values of discrepancy. In general, Figure 6 shows that, regardless of the threshold cut method used, lodging and non-lodging regions have the same patterns. The greatest differences in lodging percentage between the thresholds were found on the edges of the lodging areas, which are sensitive to the threshold cut. 

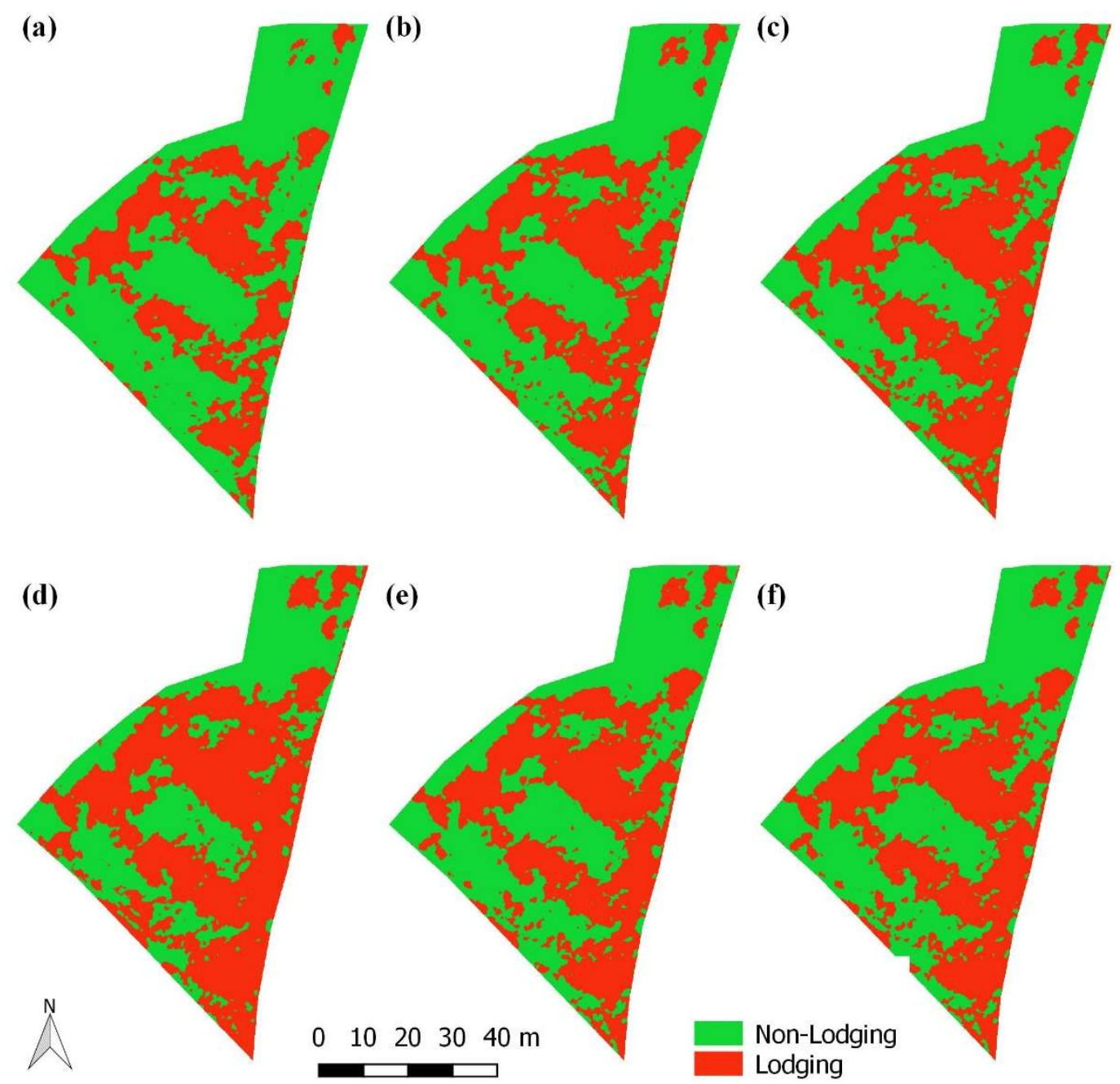

FIGURE 6. Map of the lodging and non-lodging calculated RPA-based lodging percentage for (a) $80 \%$, (b) $70 \%$, (c) $60 \%$, (d) $50 \%$, (e) iso-cluster and (f) Jenks natural breaks.

In comparison to other studies that used different methods to estimate lodging, the SfM approach, coupled with RGB images is less influenced by abiotic and external factors for lodging identification (Wilke et al., 2019). Other methods used for lodging identification may present greater limitations, due to the influence of external factors. For example, the use of thermal images to identify lodging is complex due to the influence of variations in environmental factors on the quality of the images (Wilke et al., 2019). Liu et al. (2018) used thermal images and RGB images to develop a comprehensive model of rice lodging identification. These authors obtained high values of $\mathrm{R}^{2}$ (higher than 0.9) however, the accuracy of the method was determined from textural information and was strongly dependent on a trained support vector machine (SVM) and the data set used. Changing lighting conditions during flight, general lighting, sun angle, shadow effects, plant development stages and color variation between genotypes and species may influence the method, making replication in other conditions and/or crops difficult.

The results observed in Figures 5 and 6 demonstrate the difficulty in determining a fixed value as a threshold, since this value may vary according to the culture, canopy morphology, development phase and other factors. Thus, this work presents a more feasible way to determine the threshold, based on mathematical methods that use the distribution of the data set. When comparing the Jenks and iso-cluster values with the fixed threshold value that provided the best result (Figure 7), it is possible to observe the high correlation with an $\mathrm{R}^{2}$ of 0.99 and 0.99 and an RSME of $1.66 \%$ and $2.60 \%$ for the Jenks and iso-cluster method, respectively. The variable threshold approach opens a possibility for the application of this technique in a wider range of conditions. 

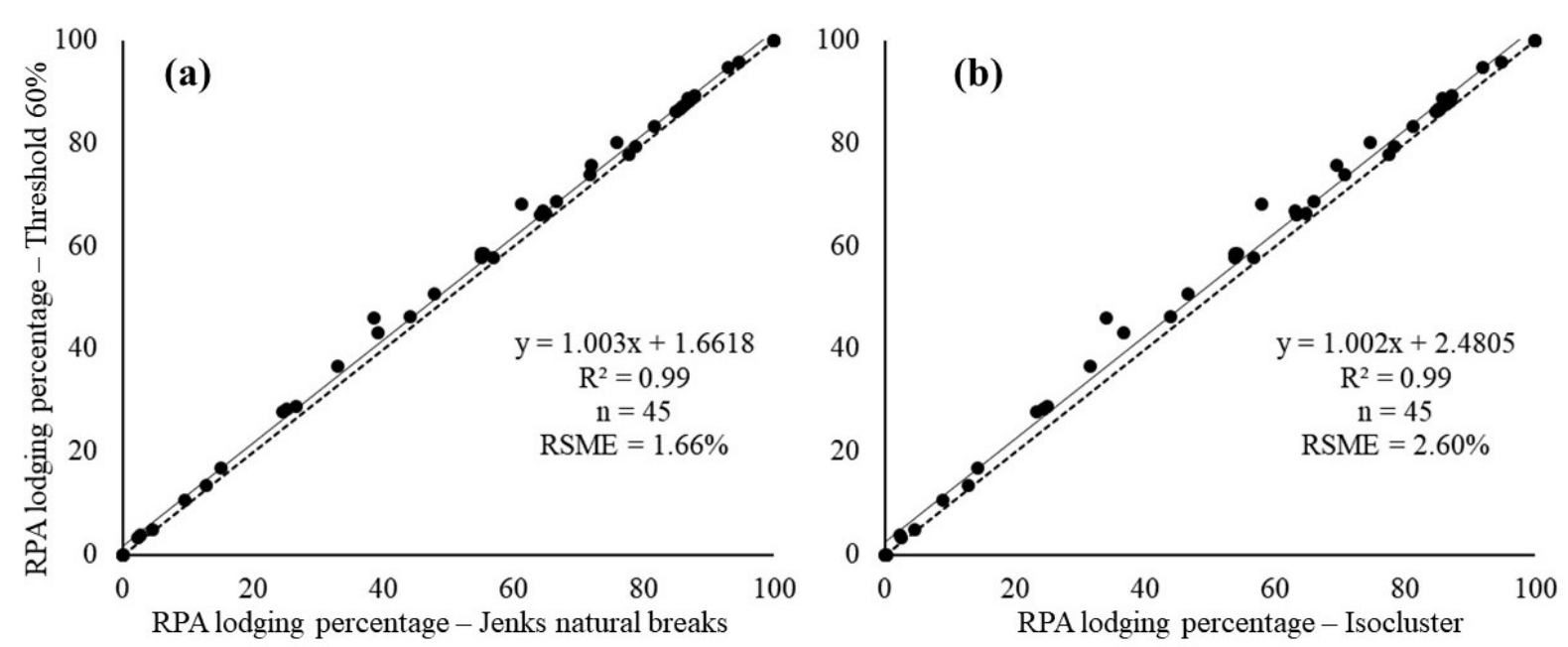

FIGURE 7. Scatter plots of RPA lodging percentage - threshold $60 \%$ and RPA-based lodging percentage for (a) Jenks natural breaks, (b) Iso-cluster. Black line represents regression line with 95\% confidence interval; dotted line represents 1:1 line (n= 45). RMSE: root mean square error.

\section{CONCLUSIONS}

The method proposed in this work has the potential to be applied to the identification and quantification of lodging areas in maize fields, with rapid data acquisition and a simplified methodology for identifying the lodging areas being the main advantages.

The non-supervised technique used to determine the variable threshold has shown great potential for identifying lodging areas, with comparable results already observed in previous studies using arbitrary thresholds.

The results show a pathway to reduce laborious manual height measurement and improve farm management using images obtained by RPA and processed through SfM. However, more improvements are needed to reduce bias and improve robustness over time.

\section{REFERENCES}

Bendig J, Bolten A, Bareth G (2013) UAV-based Imaging for Multi-Temporal, very high Resolution Crop Surface Models to monitor Crop Growth Variability. Photogrammetrie - Fernerkundung - Geoinformation 6:551-562. DOI: https://dx.doi.org/10.1127/1432$8364 / 2013 / 0200$

Bhering SB, Santos HG, Bognola IA, Cúrcio GR, Manzatto CV, Carvalho Junior WC, Chagas CS, Áglio MLD, Souza JS (2008) Mapa de solos do Estado do Paraná: legenda atualizada. In: Congresso Brasileiro de Ciência do Solo, Fortaleza, Sociedade Brasileira de Ciência do Solo, Proceedings...Available: https://www.alice.cnptia.embrapa.br/alice/bitstream/doc/57 8217/1/SP5507.pdf . Accessed: Jan 15, 2019.

Chu TX, Starek MJ, Brewer MJ, Murray SC, Pruter LS, (2017) Assessing lodging severity over an experimental maize (Zea mays L.) field using UAS images. Remote Sensing 9:923. DOI:

https://dx.doi.org/https://doi.org/10.3390/rs9090923

Elmore R (2013) Mid to Late-Season Lodging. Iowa State University Extension and Outreach. Available:

$\mathrm{http}: / /$ crops.extension.iastate.edu/corn/production/manage ment/mid/silking.html Accessed: Jan 15, 2019.
Embrapa (2010) Cultivo do Milho, Sistemas de produção 2. Embrapa Milho e Sorgo. 6(9):110. Available: https://ainfo.cnptia.embrapa.br/digital/bitstr eam/item/27037/1/Plantio.pdf . Accessed: Jan 15, 2019.

Farfan IDB, Murray SC, Labar S, Pietsch D (2013) A multi-environment trial analysis shows slight grain yield improvement in Texas commercial maize. Field Crops Research 149:167-176.

DOI: https://doi.org/10.1016/j.fcr.2013.04.017

FIESP Federação das indústrias do estado de São Paulo (2018) Safra mundial de milho. Boletim Informativo. São Paulo 12:2. Available: https://www.fiesp.com.br/arquivodownload/?id=256337. Accessed: Jan 15, 2019.

Han L, Yang G, Feng H, Zhou C, Yang H, Xu Li Z, Yang X (2018) Quantitative identification of Maize Lodgingcausing feature factors using unmanned aerial vehicle images and a nomogram computation. Remote Sensing 10:1528. DOI: https://doi.org/10.3390/rs10101528

Hoffmeister D, Bolten A, Curdt C, Waldhoff G, Bareth G (2010) High resolution Crop Surface Models (CSM) and Crop Volume Models (CVM) on field level by terrestrial laser scanning. In: International Symposium on Digital Earth: Models, Algorithms, and Virtual

Reality. Changlin Wang, International Symposium on Digital Earth, Proceedings... DOI: https://doi.org/10.1117/12.872315

Jenks GF, Caspall FG (1971) Error on choropleth maps: definition, measurement, reduction. Annals (Association of American Geographers) 61:217-

244. DOI: https://doi.org/10.1111/j.14678306.1971.tb00779.x

Li Y, Onasch CM, Guo Y (2008) GIS-based detection of grain boundaries. Journal of Structural Geology 30(4):431443. DOI: https://doi.org/10.1016/j.jsg.2007.12.007

Li Z, Chen Z, Wang L, Liu J, Zhou Q (2014) Area extraction of maize lodging based on remote sensing by small unmanned aerial vehicle. Transactions of the Chinese Society of Agricultural Engineering 30:207213. DOI: https://doi.org/10.3969/j.issn.10026819.2014.19.025 
Liu T, Li R, Zhong X, Jiang M, Jin X, Zhou P, Liu S, Sun C, Guo W (2018) Estimates of rice lodging using indices derived from UAV visible and thermal infrared images. Agricultural Forest Meteorology 252:144154. DOI: https://doi.org/10.1016/j.agrformet.2018.01.021

Malambo L, Popescu SC, Murray SC, Putman E, Pugh NA, Horne DW, Bishop M (2018) Multitemporal fieldbased plant height estimation using $3 \mathrm{D}$ point clouds generated from small unmanned aerial systems highresolution imagery. International Journal of Applied Earth Observation and Geoinformation 64:31-42.

DOI: https://doi.org/10.1016/j.jag.2017.08.014

Tilly N, Aasen H, Bareth G (2015) Fusion of Plant Height and Vegetation Indices for the Estimation of Barley

Biomass. Remote Sensing 7(9):11449-

11480. DOI: https://doi.org/10.3390/rs70911449
Wilke N, Siegmann B, Klingbeil L, Burkart A, Kraska T, Muller O, Rascher U (2019) Quantifying Lodging Percentage and Lodging Severity Using a UAV-Based Canopy Height Model Combined with an Objective Threshold Approach. Remote Sensing 11(5):515. DOI: https://doi.org/10.3390/rs11050515

Wu W, Ma BL (2016) A new method for assessing plant lodging and the impact of management options on lodging in canola crop production. Scientific Reports Journal 6:31890. DOI: https://doi.org/10.1038/srep31890

Yang MD, Huang KS, Kuo YH, Tsai HP, Lin LM (2017) Spatial and spectral hybrid image classification for rice lodging assessment through UAV imagery. Remote Sensing 9:583. DOI: https://doi.org/10.3390/rs9060583 